\title{
ANÁLISE DA DINÂMICA SAZONAL E SEPARABILIDADE ESPECTRAL DE ALGUMAS FITOFISIONOMIAS DO CERRADO COM ÍNDICES DE VEGETAÇÃO DOS SENSORES MODIS/TERRA E AQUA ${ }^{1}$
}

\author{
Veraldo Liesenberg ${ }^{2}$, Flávio Jorge Ponzoni ${ }^{3}$ e Lênio Soares Galvão ${ }^{3}$
}

\begin{abstract}
RESUMO-Composições de 16 dias de índices de vegetação do sensor MODerate resolution Imaging Spectroradiometer (MODIS), com resolução espacial de $1 \mathrm{~km}$, a bordo dos satélites TERRA e AQUA, foram usadas para caracterizar a dinâmica sazonal em 2004 de cinco fitofisionomias de Cerrado e analisar a sua separabilidade espectral. Os índices Normalized Difference Vegetation Index (NDVI) e Enhanced Vegetation Index (EVI), calculados a partir dos dados dos sensores de ambas as plataformas e de uma base comum de pixels, foram comparados entre si. Os resultados indicaram que: (a) dentre as fitofisionomias estudadas, a Floresta Estacional decídua apresentou uma dinâmica sazonal muito marcante em função da perda de folhas da estação chuvosa para a seca (substancial redução nos índices) e do rápido verdejamento com o início da precipitação no final de outubro (rápido incremento de NDVI e EVI); (b) o NDVI mostrou maior variabilidade entre as classes de vegetação do que o EVI apenas na estação seca; (c) a discriminação entre as fitofisionomias melhorou da estação chuvosa para a seca; (d) o NDVI foi mais eficiente do que o EVI para discriminar as classes de vegetação na estação seca, ocorrendo o contrário na estação chuvosa; e (e) na maioria das datas selecionadas para estudo, não houve diferenças estatisticamente significativas entre os índices de vegetação gerados de ambas as plataformas, apesar das variações na qualidade dos pixels selecionados para as composições de 16 dias e na geometria de iluminação e de visada.
\end{abstract}

Palavras-chave: Sensoriamento remoto, MODIS, NDVI, EVI, índices de vegetação e Cerrado.

\section{ANALYSIS OF THE SEASONAL DYNAMICS AND SPECTRAL SEPARABILITY OF SOME SAVANNA PHYSIOGNOMIES WITH VEGETATION INDICES DERIVED FROM MODIS/TERRA AND AQUA}

\begin{abstract}
MODerate-resolution Imaging Spectroradiometer (MODIS) 16-day vegetation index composites with $1 \mathrm{~km}$ of spatial resolution from TERRA and AQUA satellites were used to characterize the seasonal dynamics of five Brazilian savanna physiognomies and to analyze their spectral separability in 2004. The Normalized Difference Vegetation Index (NDVI) and Enhanced Vegetation Index (EVI), using data from both platforms and from a common set of pixels, were compared to each other. The results showed that: (a) among the physiognomies under study, Dry Forest (Floresta Estacional decídua) presented a marked seasonal dynamics as a result of the leaffall from the rainy to the dry season (strong decrease in the indices) and of the fast green up of vegetation with precipitation at the end of October (strong and rapid increase in NDVI and EVI
\end{abstract}

\footnotetext{
${ }^{1}$ Recebido em 25.09.2006 e aceito para publicação em 13.03.2007.

${ }^{2}$ Bolsista PCI-DTI/CNPq. E-mail:<vlberg@ltid.inpe.br>.

${ }^{3}$ Instituto Nacional de Pesquisas Espaciais - Divisão de Sensoriamento Remoto - Avenida dos Astronautas, 1758, 12227-010 São José dos Campos, SP - Brasil.
} 
values); (b) NDVI showed greater variability between the vegetation classes than EVI only in the dry season; (c) the discrimination between the physiognomies improved from the rainy to the dry season; (d) the NDVI was more efficient than EVI to separate the vegetation classes in the dry season, but the contrary was observed in the rainy season; and (e) for the majority of the dates under analysis, in spite of the variations in the quality of the pixels selected to compose the vegetation index MODIS product and in the Sun-view geometry, no statistically significant differences between the indices generated from both platforms were observed.

Keywords: Remote sensing, MODIS, NDVI, EVI, vegetation indices and Brazilian Savanna.

\section{INTRODUÇÃO}

Diante da necessidade de monitorar e caracterizar os ciclos sazonais da vegetação, vários instrumentos orbitais têm sido desenvolvidos e aperfeiçoados. Como exemplo, pode ser citado o sensor MODerate resolution Imaging Spectroradiometer (MODIS) a bordo dos satélites TERRAe AQUA, que foram lançados em 1999 e 2002, respectivamente. O horário de passagem de ambos os satélites pela linha do Equador é diferenciado (10h30 para o TERRA e 13 h30 para o AQUA), o que favorece um imageamento diário do globo terrestre com uma resolução espacial moderada (JUSTICE et al., 1998). A alta resolução temporal do MODIS é um aspecto determinante em estudos fenológicos e na discriminação espectral, podendo ser utilizada para obter conhecimento aprofundado a respeito dos ciclos sazonais da vegetação em biomas com forte contraste sazonal, como o Cerrado.

Índices de vegetação, que são combinações de dois ou mais comprimentos de onda designados para realçar alguma propriedade da vegetação, são comumente utilizados para avaliar aspectos sazonais de fitofisionomias de biomas distintos em estudos regionais e globais (FRANÇA e SETZER, 1998; GURGEL e FERREIRA, 2003; DESSAY et al., 2004; FERREIRA e HUETE, 2004; SANO et al., 2005; LIESENBERG et al., 2007). Segundo Huete et al. (2002), as composições de índices de vegetação de 16 dias do sensor MODIS permitem análises regulares da vegetação em nível global, incluindo a avaliação de aspectos fenológicos e a detecção de mudanças. Essas análises não podem ser feitas com sensores de baixa resolução temporal como os da série Landsat.

Inseridos nesse contexto, os objetivos deste trabalho foram: (1) utilizar os índices de vegetação Normalized Difference Vegetation Index (NDVI) e o Enhanced Vegetation Index (EVI) gerados pelo sensor MODIS para caracterizar a dinâmica sazonal, no ano de 2004, de cinco fitofisionomias do Cerrado em uma área de estudo localizada nos Estados de Minas Gerais e Bahia; (2) analisar a separabilidade espectral delas com os índices de vegetação; e (3) comparar o desempenho dos índices oriundos das plataformas TERRA e AQUA para caracterizar essa dinâmica. Visto que a aquisição de dados por ambas as plataformas representa condições distintas de geometria de visada e de iluminação, esta comparação se justifica para avaliar se essas condições afetam a detecção da dinâmica sazonal das fitofisionomias pelos sensores MODIS/TERRA e AQUA em estudos voltados para o monitoramento contínuo desse bioma.

\section{MATERIAL E MÉTODOS}

\subsection{Localização e descrição da área de estudo}

A área de estudo está localizada no noroeste do Estado de Minas Gerais (MG) e sudoeste da Bahia (BA), próximo à divisa do Estado de Goiás (GO) (Figura 1). Devido à importância arqueológica, espeleológica e biológica da região, a área de estudo conta com várias unidades de conservação, entre as quais se destacam: a Área de Proteção Ambiental Cavernas do Peruaçu, os Parques Estaduais Veredas do Peruaçu, Verde Grande, Mata Seca e Lagoa do Cajueiro, o Parque Nacional Cavernas do Peruaçu e a Reserva Biológica do Jaíba.

Em relação à cobertura vegetal, há cinco fitofisionomias predominantes. De acordo com o sistema brasileiro de classificação da vegetação (IBGE, 1992), as fitofisionomias são Floresta Estacional semi-decídua, Floresta Estacional decídua, Floresta Pluvial, Savana Arborizada e Savana Parque. Segundo o sistema de classificação do Cerrado proposto por Ribeiro e Walter (1998), as fitofisionomias Floresta Estacional decídua, Savana Arbórea e Savana Parque são equivalentes à Mata Seca, ao Cerrado stricto sensu e ao Cerrado ralo, respectivamente. 


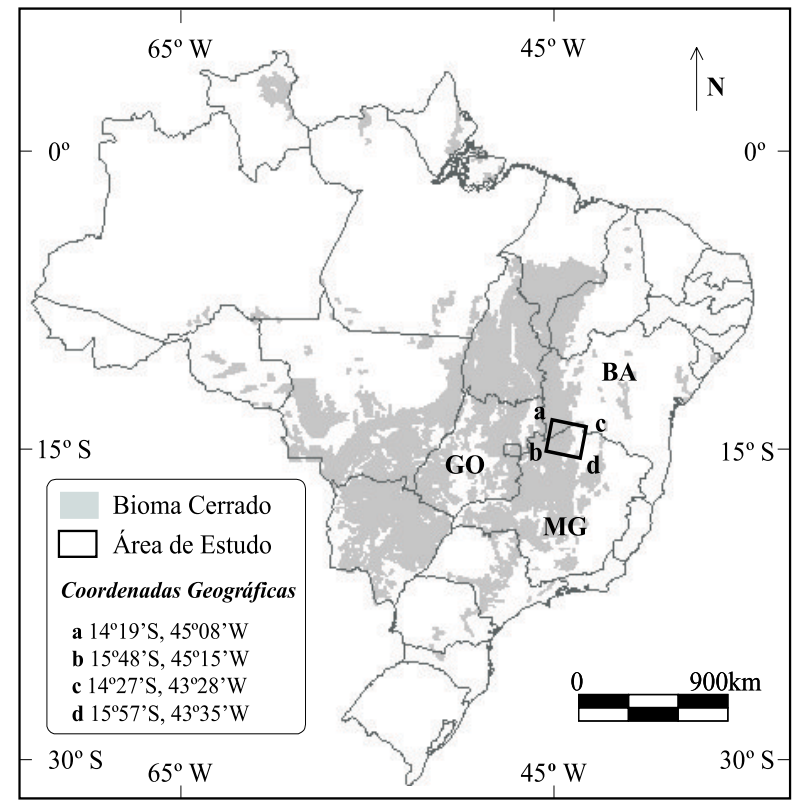

Figura 1 - Localização da área de estudo dentro do contexto nacional. A delimitação do bioma Cerrado também é apresentada.

Figure 1 - Location of the study area within the national context. The delimitation of the Cerrado biome is also presented.

A deciduidade na estação seca varia de 20 a $50 \%$ para a Floresta Estacional semi-decídua, e é maior do que $50 \%$ para a Floresta Estacional decídua. A Floresta Pluvial ocorre em áreas próximas ao rio São Francisco e abrange uma variedade de tipologias. As fisionomias Savana Arbórea e Savana Parque apresentam pequenas palmeiras, arbustos retorcidos e inclinados sobre um substrato de gramíneas, enquanto a Savana Arbórea apresenta um estrato arbóreo dominante e um maior porcentual de cobertura de copas do que a Savana Parque. Para demonstrar melhor as diferenças biofísicas entre as fitofisionomias sob análise, no Quadro 1 são mostrados os parâmetros biofísicos coletados em 38 parcelas durante a estação chuvosa e, de forma complementar, os dados do produto Vegetation Continuous Field (HANSEN et al., 2002) que foram obtidos através de processamentos de dados do sensor MODIS durante o período de novembro a dezembro de 2001 (início da estação chuvosa).

De acordo com os resultados desse quadro, a cobertura de dosséis, calculada pela projeção vertical das copas, decresce da Floresta Estacional semi-decídua e Floresta Estacional decídua para as demais fitofisionomias. A Floresta Pluvial apresenta o maior valor de área basal, enquanto a Savana Parque, os menores valores de altura média. O DAP e o diâmetro médio das copas descrescem da Floresta Estacional semidecídua e Savana Arbórea para as outras fitofisionomias. Finalmente, as maiores proporções de indivíduos arbóreos foram observadas para a Floresta Pluvial e Estacional semi-decídua. De acordo com o produto MODIS Vegetation Continuous Field, o porcentual de cobertura de dosséis decresce em ordem da Floresta Estacional decídua e Floresta Estacional semi-decídua para Savana Arbórea, Floresta Pluvial e Savana Parque. A fisionomia Savana Parque apresentou a maior proporção de cobertura herbácea, enquanto a Savana Arbórea e a Savana Parque apresentaram reduzidas proporções de solo exposto.

Quadro 1 - Valores médios e de desvio-padrão de parâmetros biofísicos medidos na estação chuvosa das cinco fitofisionomias em análise

Table 1 - Average and standard deviation values of vegetation parameters measured in the rainy season for the five physiognomies under study

\begin{tabular}{|c|c|c|c|c|c|}
\hline \multirow{3}{*}{$\begin{array}{l}\text { Parâmetro Biofísico } \\
\text { Cobertura dosséis (\%) }\end{array}$} & \multicolumn{5}{|c|}{ FITOFISIONOMIAS } \\
\hline & FESD & FED & SA & SP & FP \\
\hline & $72,11 \pm 21,93$ & $61,79 \pm 16,33$ & $46,57 \pm 14,92$ & $30,99 \pm 10.44$ & $41,29 \pm 23,77$ \\
\hline Area Basal $\left(\mathrm{m}^{2} / \mathrm{ha}\right)$ & $55 \pm 16$ & $62,5 \pm 13$ & $53 \pm 12$ & $37 \pm 12$ & $88 \pm 14$ \\
\hline $\mathrm{DAP}(\mathrm{cm})$ & $14,20 \pm 0,84$ & $8,78 \pm 4,32$ & $11,55 \pm 4,49$ & $9,13 \pm 1.28$ & $5,81 \pm 1,16$ \\
\hline Altura (m) & $6,11 \pm 1,78$ & $4,25 \pm 1,84$ & $4,80 \pm 2,07$ & $2,99 \pm 0.75$ & $4,67 \pm 0,36$ \\
\hline Diâmetro da Copa (m) & $2,93 \pm 1,36$ & $2,43 \pm 1,33$ & $3,13 \pm 2,35$ & $1,44 \pm 0.34$ & $1,02 \pm 0,40$ \\
\hline Indivíduos por ha & $1475 \pm 515$ & $3222 \pm 1360$ & $1454 \pm 552$ & $1620 \pm 757$ & $3063 \pm 398$ \\
\hline Cobertura Arbórea $(\%)^{*}$ & $55,62 \pm 10,28$ & $50,70 \pm 11,01$ & $39,60 \pm 10,37$ & $25,20 \pm 9,56$ & $36,85 \pm 13,13$ \\
\hline Cobertura Herbácea $(\%)^{*}$ & $44,36 \pm 10,26$ & $49,3 \pm 11$ & $59,70 \pm 10,08$ & $71,66 \pm 7,29$ & $63,15 \pm 13,13$ \\
\hline Solo exposto $(\%)^{*}$ & - & - & $0,7 \pm 0,85$ & $3,13 \pm 3,87$ & - \\
\hline
\end{tabular}

Nota: FESD = Floresta Estacional semi-decídua $;$ FED = Floresta Estacional decídua; $\mathrm{SA}=\mathrm{Savana}$ Arbórea $; \mathrm{SP}=\mathrm{Savana}$ Parque $;$ FP = Floresta Pluvial; e DAP = Diâmetro a Altura do Peito. * Valores obtidos a partir do produto Vegetation Continuous Field (HANSEN et al., 2002). 
O clima da região é caracterizado por estações chuvosa (novembro a abril) e seca (maio e outubro) bem definidas. A Figura 2 mostra a média mensal pluviométrica da área de estudo baseada em oito estações pluviométricas, considerando uma média histórica de 30 anos e durante o período de aquisição dos dados orbitais sob análise. De acordo com essa figura, podese observar que, em geral, a média anual de precipitação é de $925 \mathrm{~mm}$, e um porcentual superior a $85 \%$ concentrase na estação chuvosa. Percebe-se também que o ano de 2004 foi atípico em relação à média histórica de 30 anos, em que a precipitação foi menor de janeiro a março e maior de setembro a dezembro.

\subsection{Aquisição dos dados MODIS}

Foi utilizado um banco de dados contendo 46 datas dos produtos MOD13A2 (MODIS/TERRA) e MYD13A2 (MODIS/AQUA), respectivamente, correspondentes ao ano de 2004. Assim, um conjunto de 23 imagens MODIS de cada satélite foi utilizado. Os dados incluem os índices de vegetação NDVI e EVI com 1 km de resolução espacial, quatro bandas espectrais radiometricamente calibradas, georetificadas e espacialmente co-registradas entre si: azul (459-479 nm), vermelho (620-670 nm) infravermelho próximo (841-876 nm) e infravermelho de ondas curtas (2105-2155 nm) e informações da geometria de aquisição dos dados.

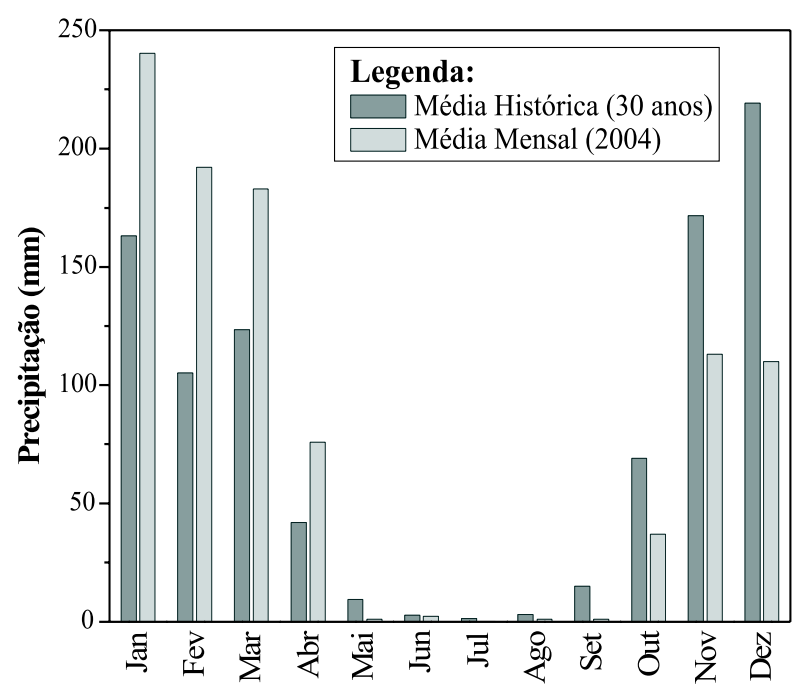

Figura 2 - Precipitação média mensal e média histórica de 30 anos.

Figure 2-Monthly average precipitation and 30-year historic average.

R. Árvore, Viçosa-MG, v.31, n.2, p.295-305, 2007
O algoritmo usado para gerar os produtos MOD13 e MYD13 opera pixel-a-pixel e requer múltiplas observações (16 dias) do produto reflectância de superfície (Fator de Reflectância Bidirecional - MOD09 para TERRA e MYD09 para AQUA, respectivamente) como dado de entrada para gerar os índices NDVI e EVI. Os produtos MOD09 e MYD09 já são corrigidos dos efeitos atmosféricos. Uma vez que todos os dados do período de 16 dias são coletados, o algoritmo aplica um filtro nos dados com base na qualidade, ou seja, cobertura de nuvens e geometria de visada (HUETE et al., 1999).

Segundo Huete et al. (2002), as composições de 16 dias contendo os índices NDVI e EVI dos produtos MOD13 e MYD13 são designadas para monitorar padrões temporais e espaciais da atividade fotossintética globalmente, incluindo a avaliação de aspectos fenológicos e a detecção de mudanças. O NDVI pode ser obtido pela equação:

$N D V I=\left(\frac{\rho_{(I V P)}-\rho_{(\text {Vermelho })}}{\rho_{(I V P)}+\rho_{(\text {Vermelho })}}\right)$ [adimensional] Eq. 2.1 em que:

$N D V I=$ Normalized Difference Vegetation Index;

$\rho_{\text {(Vermelho) }}=$ fator de reflectância bidirecional na banda do vermelho; e

$\rho_{\mathrm{IVP}}=$ fator de reflectância bidirecional na banda do IVP.

O EVI foi desenvolvido para otimizar a resposta da vegetação verde melhorando a sensibilidade para as variações estruturais e arquitetônicas do dossel de fitofisionomias com maior densidade de biomassa em relação ao NDVI e reduzindo as influências atmosféricas e influência do solo (HUETE et al., 2002). O EVI pode ser obtido da equação:

$$
E V I=\left(\frac{\rho_{(I V P)}-\rho_{(\text {Vermelho })}}{\rho_{(I V P)}+C_{1} \rho_{(\text {Vermelho })}-C_{2} \rho_{(\text {Azul })}+L}(G)\right)
$$

[adimensional]

Eq. 2.2

em que:

$E V I=$ Enhanced Vegetation Index;

$\rho_{(\text {Azul })}, \rho_{\text {(Vermelho) }}$ e $\rho_{I V P}=$ fatores de reflectância bidirecional nas bandas espectrais do azul, vermelho e IVP, respectivamente; 
$C_{1}$ e $C_{2}=$ coeficientes de ajuste para efeito de aerossóis da atmosfera para a banda do vermelho e azul, respectivamente;

$$
\begin{aligned}
& L=\text { fator de ajuste para o solo; e } \\
& G=\text { fator de ganho. }
\end{aligned}
$$

Segundo Huete et al. (1997), os coeficientes para os sensores MODIS são $\mathrm{L}=1, \mathrm{C}_{1}=6, \mathrm{C}_{2}=7,5$ e $\mathrm{G}=2,5$.

\subsection{Seleção de pixels e análise de dados}

Um conjunto comum de 10 pixels para cada classe foi considerado para cada uma das composições de 16 dias do sensor MODIS no ano de 2004, bem como para cada plataforma. A seleção do conjunto comum de 10 pixels de cada fitofisionomia foi baseada na análise de mapas de vegetação (IBGE, 2004) e na execução de campanhas de campo para a caracterização e a seleção de áreas representativas de cada fitofisionomia estudada. Os valores médios dos índices NDVI e EVI foram extraídos e plotados em função de 23 datas julianas de aquisição com os respectivos desvios-padrão de cada satélite. Cada data juliana utilizada corresponde ao período médio da composição de 16 dias. Perfis espectrais elaborados a partir de dados de diferentes datas e representando condições extremas de sazonalidade também foram plotados em função do comprimento de onda. Considerando que as imagens são constituídas por pixels registrados em diferentes datas e condições angulares de aquisição (iluminação e de visada), essas variações também foram consideradas neste trabalho.

O teste $t$ de Student foi empregado para verificar se as diferenças encontradas entre os índices de vegetação de ambas as plataformas (TERRA e AQUA) foram significativamente diferentes. Assim, pôde-se avaliar se a caracterização espectral de dada fisionomia foi diferenciada pela adoção de dados de uma ou de outra plataforma.

Na última etapa do trabalho, calculou-se a Distância Euclideana entre pares de fitofisionomias usando os índices de vegetação NDVI e EVI. Quanto menor a distância Euclideana, menor o potencial do índice para discriminar o par de fitofisionomias analisado. A Distância Euclideana pode ser obtida da equação:

$D E=\sqrt{\sum_{i=1}^{n}\left(x_{i}-y_{i}\right)^{2}}$ [adimensional] em que:

$D E=$ distância Euclideana;

$x_{i}=$ valor do índice de vegetação para a classe $\mathrm{x}$ no pixel i (enumeração completa);

$y_{i}=$ valor do índice de vegetação para a classe y no pixel i (procedimento amostral); e

$\mathrm{n}=$ número de variáveis.

\section{RESULTADOS E DISCUSSÃO}

A dinâmica sazonal da vegetação da área de estudo é mostrada na Figura 3. A distribuição espacial dos pixels de referência selecionados para análise das cinco fitofisionomias também foi indicada nessa figura. Da estação chuvosa (Figura 3a) para a seca (Figura 3b), a principal modificação na composição colorida é a diminuição da cor verde associada à banda do IVP, que reflete o espalhamento da radiação pela vegetação verde.

A Figura 4 ilustra os perfis de NDVI e EVI, obtidos a partir da plataforma TERRA, para as cinco fitofisionomias estudadas. A dinâmica sazonal da vegetação é evidente nesses perfis, com a estação seca (maio a outubro) produzindo os menores valores de NDVI e EVI e a estação chuvosa (novembro a abril), os maiores valores desses índices. Na estação chuvosa, as fitofisionomias com dosséis mais densos (Floresta Estacional decídua e semi-decídua, e a Floresta Pluvial) mostraram maiores valores de NDVI e EVI do que a Savana Arbórea e a Savana Parque. Do final da estação chuvosa para a estação seca, todas as fitofisionomias mostraram sensível decréscimo nos índices de vegetação. Para algumas fitofisionomias, essa tendência está associada à perda de folhas na estação seca. A Floresta Estacional decídua, por exemplo, com perda quase total de folhas, mostrou forte redução nos valores de NDVI

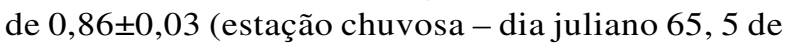

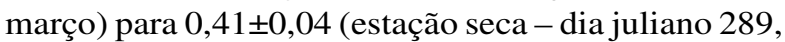
15 de outubro) (Figura 4a).

A comparação entre os perfis das Figuras 4a e 4b mostrou que o NDVI apresentou maior variabilidade entre as classes de vegetação do que o EVI na estação seca, mas o contrário ocorreu na estação chuvosa, em concordância com as observações feitas por Ratana et al. (2005). Entretanto, o efeito de verdejamento abrupto da Floresta Estacional decídua na transição do final da estação seca para o início da estação chuvosa foi

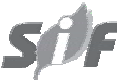

R. Árvore, Viçosa-MG, v.31, n.2, p.295-305, 2007 
mais pronunciado no perfil de NDVI. Vale salientar que a avaliação desse efeito seria dificultada quando da utilização de sensores tradicionalmente explorados como os da série Landsat, em função da sua baixa resolução temporal.

Para ilustrar o efeito de verdejamento das fitofisionomias indicado na Figura 4, a Figura 5 mostra

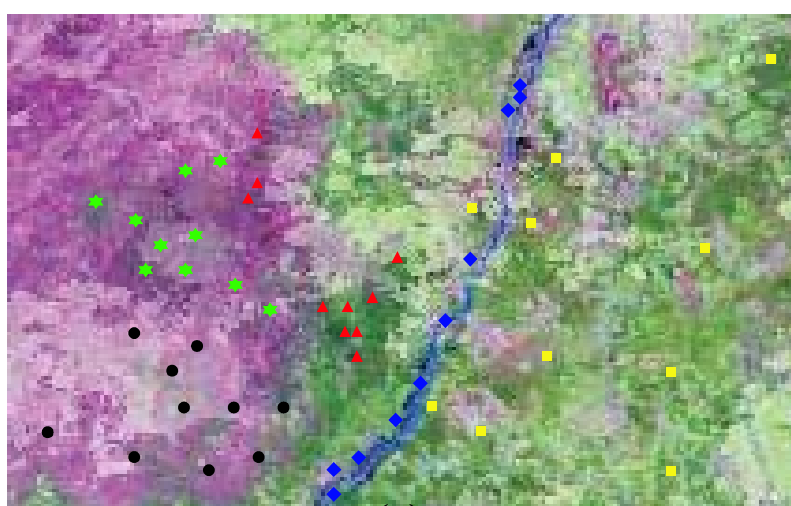

(a) os espectros de reflectância (Fator de Reflectância Bidirecional) do MOD13. As datas selecionadas para a extração dos espectros foram os dias julianos: 65 (5 de março, Figura 5a), por representar a estação chuvosa; 289 (15 de outubro, Figura 5b), por representar o final da estação seca; e 305 (31 de outubro, Figura $5 c)$, por representar o efeito de verdejamento, que é variável de acordo com a fitofisionomia em análise.

\footnotetext{
- Floresta Pluvial - Floresta Estacional dec ídua $\quad$ Floresta Estacional semi -decídua

* Savana Arbórea

- Savana Parque
}

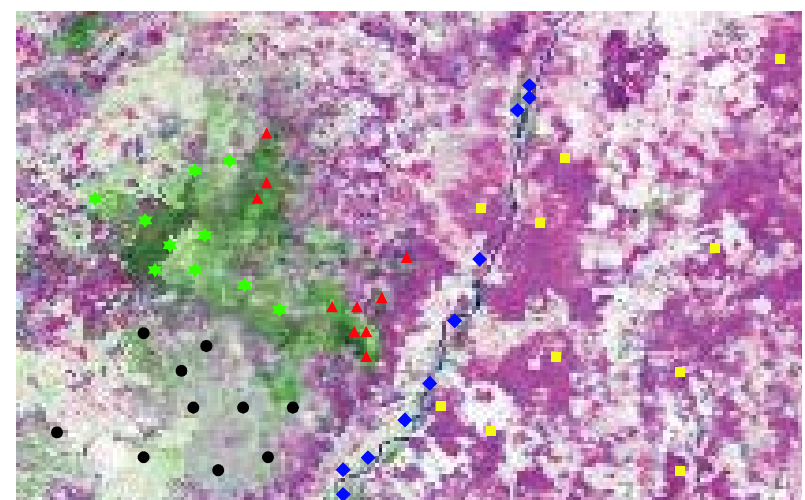

(b)

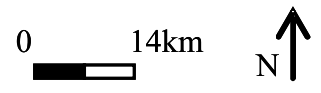

Figura 3 - Contraste sazonal da vegetação ilustrado por composições coloridas (IVM, IVPe Vermelho em RGB) do sensor MODIS adquiridas em: (a) 5 de março (estação chuvosa) e (b) 15 de outubro (estação seca). A distribuição espacial dos pontos selecionados das cinco fitofisionomias está indicada por símbolos.

Figure 3 - Seasonal contrast of vegetation illustrated by MODIS color composites (MIR, NIR and Red in RGB) collected in: (a) March, 5 (rainy season) and (b) October, 15 (dry season). The spatial distribution of selected points for the five physiognomies is indicated by symbols.

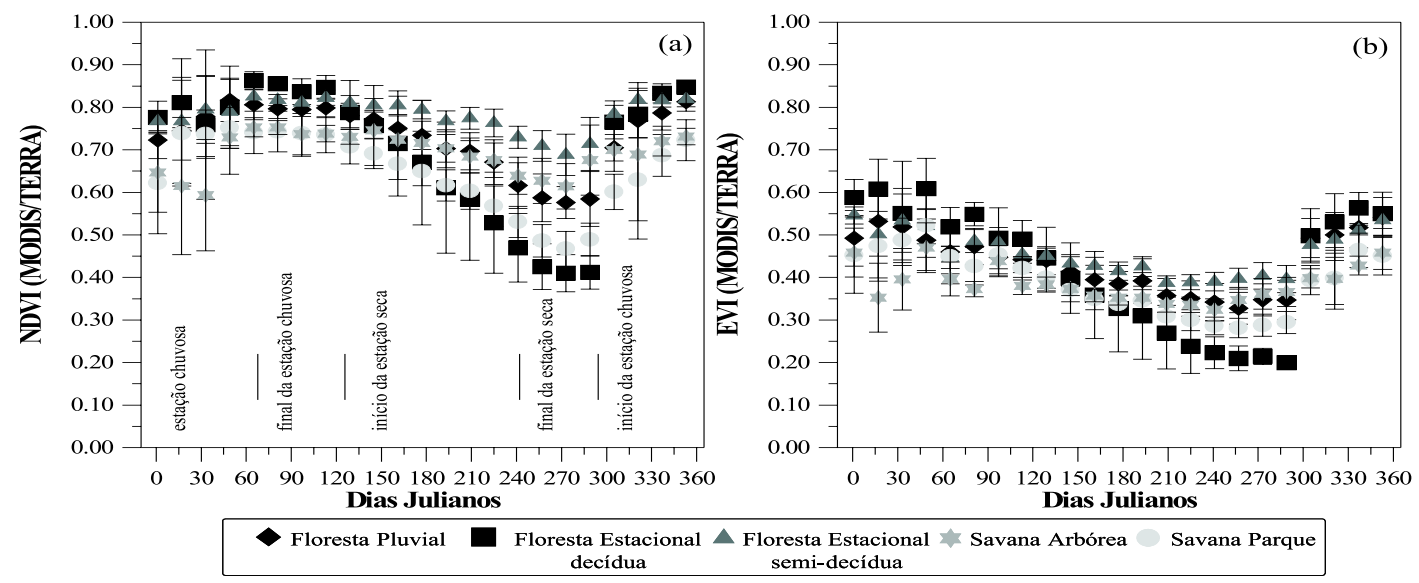

Figura 4 - Variações sazonais do (a) NDVI e (b) EVI obtidos do sensor MODIS a bordo da plataforma TERRA. A média e o desvio-padrão de 10 pixels são indicados.

Figure 4-Seasonal variations of (a) NDVI and (b) EVI obtained from the MODIS sensor onboard TERRA platform. Average and standard deviation of 10 pixels are indicated.

R. Árvore, Viçosa-MG, v.31, n.2, p.295-305, 2007

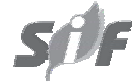


De acordo com Ratana et al. (2005), o efeito de verdejamento tende a ser menor para as formações herbáceas do que para fitofisionomias de estrato arbóreo devido ao fluxo mais acelerado de crescimento que ocorre comas espécies arbóreas. Acomparação das Figuras 5b e 5c confirma o fato de a Floresta Estacional decídua ser a fitofisionomia que responde de forma mais rápida ou abrupta, ao início da estação chuvosa, em concordância com os resultados dos índices de vegetação (Figura 4). Da Figura 5b para a Figura 5c, há uma reduçãodareflectânciano vermelho(absorçãoporclorofila), um aumento da reflectância no infravermelho próximo (espalhamento da radiação pela estrutura interna das folhas e componentes do dossel) e uma diminuição da reflectância no infravermelho de ondas curtas (absorção da radiação pela umidade das folhas).
De acordo com os espectros da Figura 5, a discriminação entre as fitofisionomias é facilitada no final da estação seca (Figura 5b), que mostra maior separabilidade entre as curvas. Para confirmar esta tendência com índices de vegetação, a Figura 6 ilustra as variações da distância Euclideana para cada período de 16 dias usando dados do NDVI e EVI para a discriminação de dois pares de fitofisionomias: Floresta Estacional decídua versus semi-decídua (Figura 6a) e Savana Arbórea versus Savana Parque (Figura 6b). Em cada índice e figura, os valores médios acima das linhas tracejadas foram estatisticamente significativos (teste $t$ de Student, em nível de $95 \%$ de probabilidade), com relação à menor distância média encontrada.
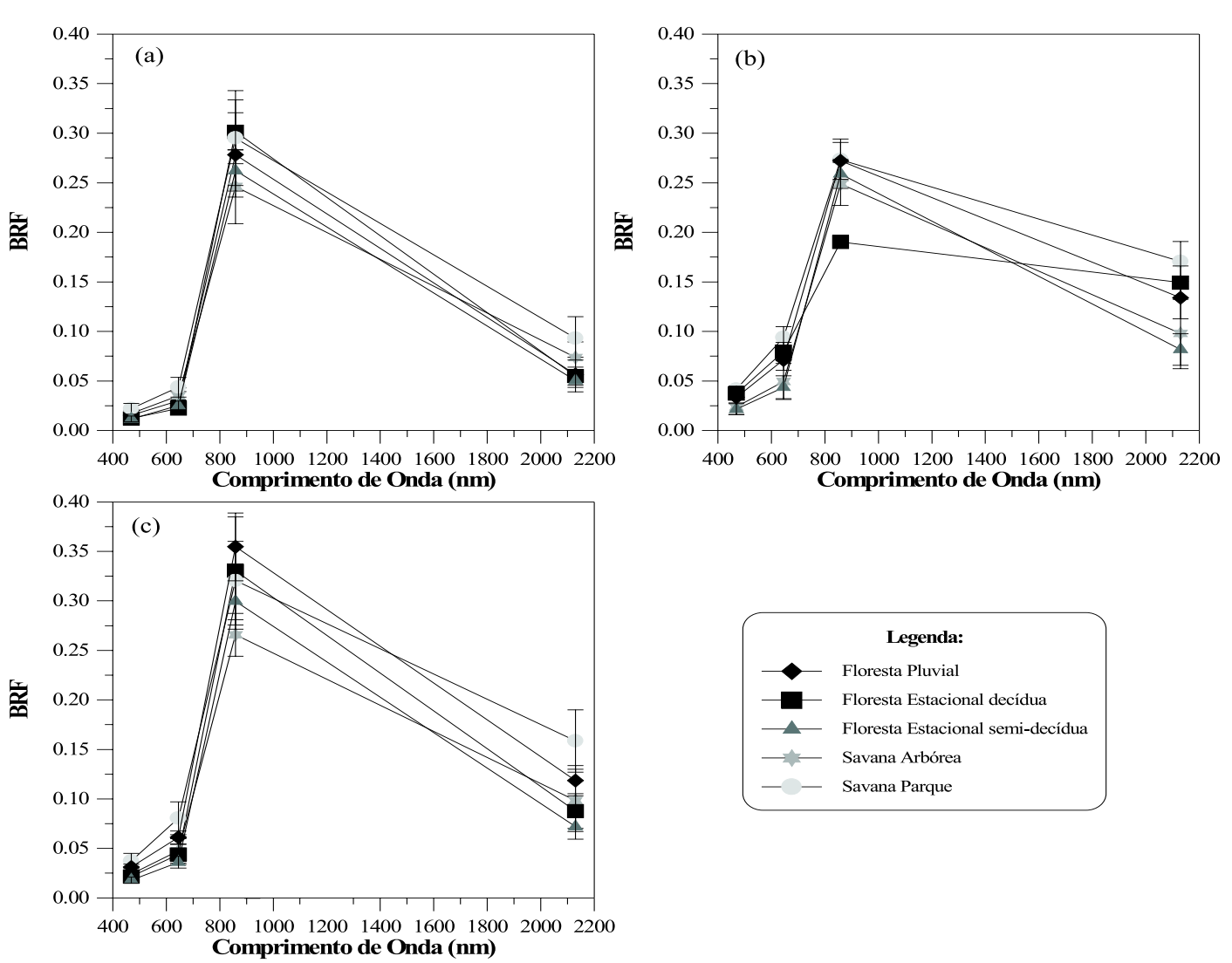

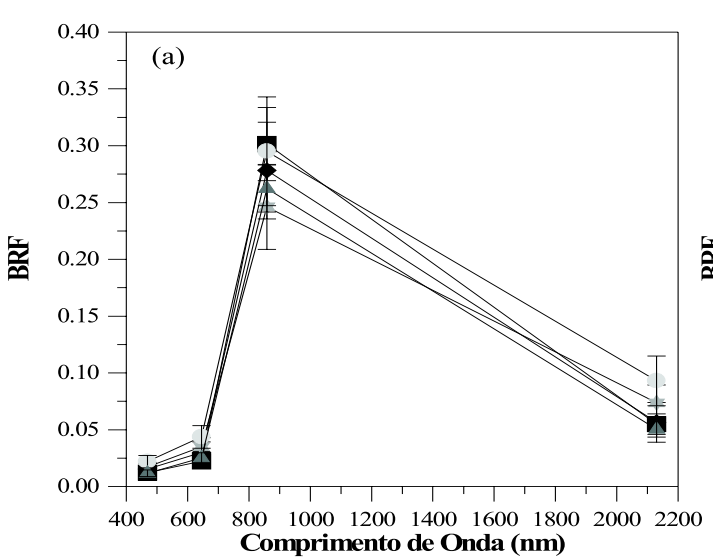

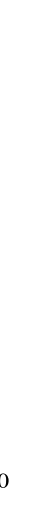

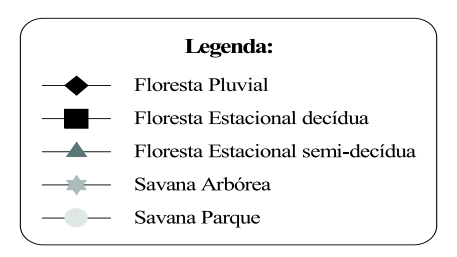

Figura 5 - Fator de Reflectância Bidirecional (FRB) de cinco fitofisionomias. Médias e desvio-padrão calculados a partir de 10 pixels de cada classe são indicados. Os dados foram adquiridos em: (a) dia Juliano 65 (5 de março); (b) 289 (15 de outubro); e (c) 305 (31 de outubro). Os símbolos indicam o centro das bandas espectrais do sensor MODIS.

Figure 5 - Bidirectional Reflectance Factor (BRF) of five physiognomies. Average and standard deviation values calculated with 10 pixels for each physiognomy are indicated. Data were acquired in: (a) Julian day 65 (March, 5); (b) 289 (October, 15); and (c) 305 (October, 31). The symbols indicated the centre of the MODIS spectral bands. 
Os resultados mostrados nessas figuras confirmam o aumento nos valores de distância Euclideana da estação chuvosa para a seca, período em que máxima discriminação entre as fitofisionomias foi observada. Esses resultados corroboram os trabalhos prévios desenvolvidos por Ferreira e Huete (2004), Ratana et al. (2005), Sano et al. (2005) e Liesenberg et al. (2007). De maneira geral, esses autores concluíram que, no final da estação seca, a discriminação entre as fitofisionomias do bioma Cerrado foi maximizada. Neste estudo, embora o EVI tenha sido desenvolvido para otimizar o desempenho do NDVI, os resultados apresentados na Figura 6 indicam que o NDVI mostrou melhor poder de discriminação espectral na estação seca do que o EVI, mas o contrário ocorreu na estação chuvosa, período em que o EVI teve maior variabilidade do que o NDVI (Figura 4).

Os perfis de NDVI e EVI para as cinco fitofisionomias estudadas, obtidos a partir da plataforma AQUA, são apresentados na Figura 7. Uma comparação visual entre os perfis das Figuras 7 (MODIS/AQUA) e 4 (MODIS/ TERRA) apontou concordância entre os valores médios dos índices NDVI e EVI entre as plataformas. De fato, essa tendência foi confirmada com a aplicação do teste $t$ de Student para comparação dos valores médios de NDVI e EVI, em nível de $95 \%$ de probabilidade. Para o NDVI, de um total de 23 datas, somente o seguinte número de datas apresentou diferenças significativas estatisticamente entre as duas plataformas (TERRA e AQUA) para as fitofisionomias específicas: Floresta Pluvial (duas datas), Floresta Estacional decídua (três datas) e semi-decídua (cinco datas), Savana Arbórea (cinco datas) e Savana Parque (duas datas). Portanto, em geral, não houve diferenças estatisticamente significativas na maioria das datas. As poucas datas que mostraram tais diferenças estiveram associadas à estação chuvosa, período em que a qualidade dos pixels selecionados para compor os produtos MOD13 e MYD13 tende a diminuir em função da cobertura de nuvens.
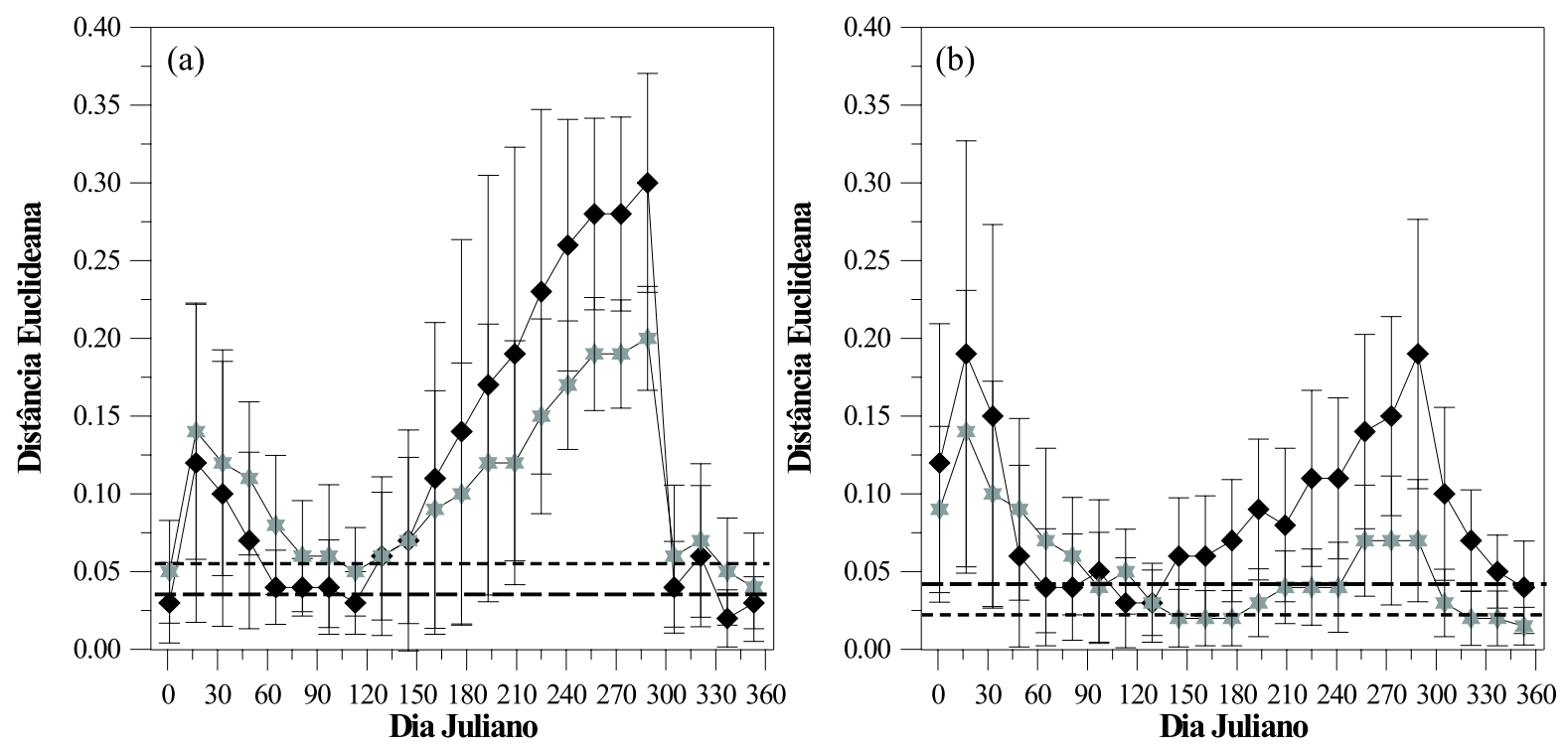

NDVI - - NDVI (teste-t, $\mathrm{p}<0,05)$

EVI $\quad----$ EVI (teste- $t, \mathrm{p}<0,05)$

Figure 6 - Variações nos valores da distância euclideana (média e desvios-padrão de 10 pixels), em função da sazonalidade e do dia Juliano para a discriminação entre (a) Floresta Estacional Decídua e Semi-Decídua; e (b) Savana Arborizada e Savana Parque. Valores acima da linha horizontal tracejada são estatisticamente diferentes (teste t, em nível de significância de 0,05 ) da menor distância média de cada índice e figura.

Figure 6-Variations in Euclidean distance values (Average and standard deviations of 10 pixels) as a function of seasonality and Julian day for the discrimination between (a) Floresta Estacional decídua and semi-decídua; and (b) Savana Arborizada and Savana Parque. Values above the horizontal dashed line are statistically different (t-test; significance level of 0.05) from the lowest mean distance of each index and figure.

R. Árvore, Viçosa-MG, v.31, n.2, p.295-305, 2007 

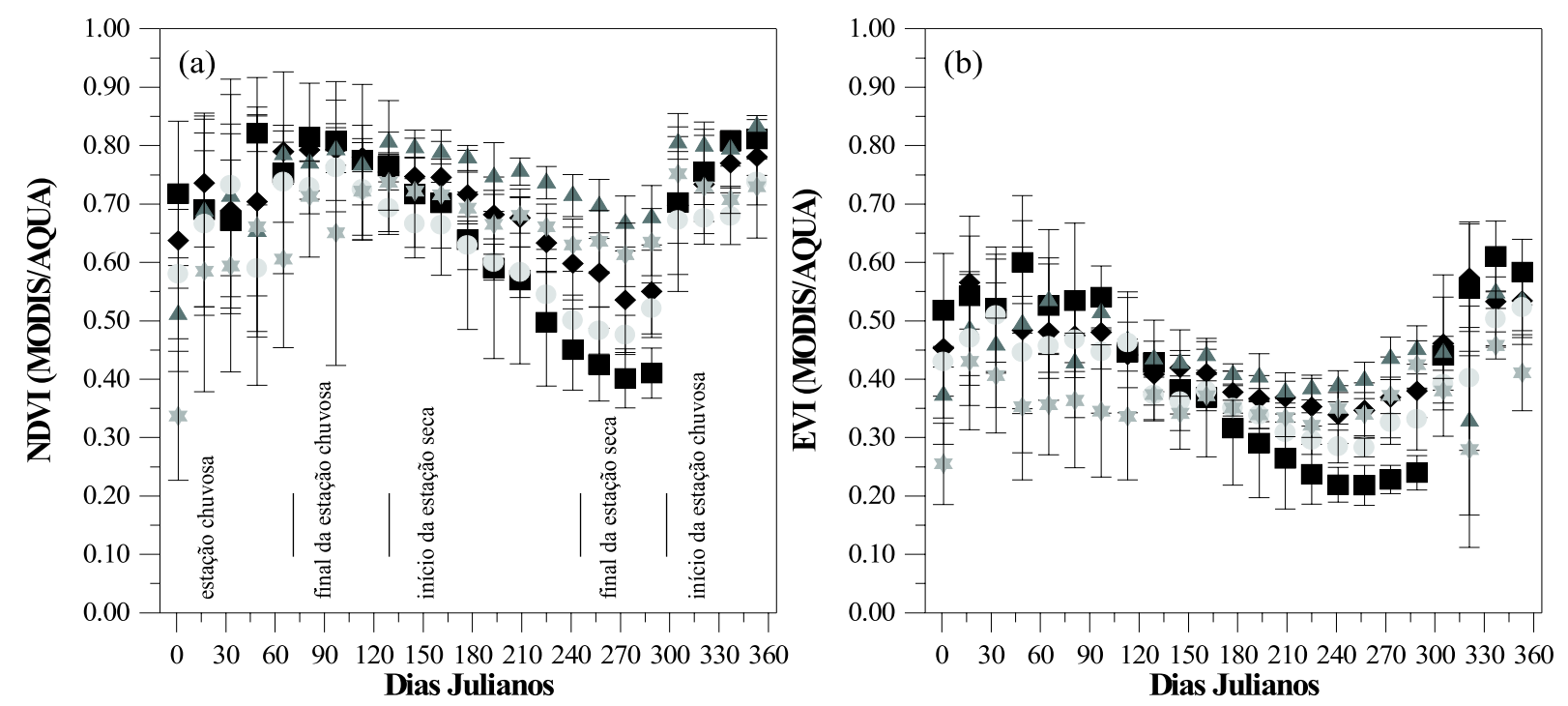

Floresta Pluvial

Floresta Estacional $\Delta$ Floresta Estacional Savana Arbórea Savana Parque decídua semi-decídua

Figura 7 - Variações sazonais do (a) NDVI; e (b) EVI obtidos do sensor MODIS a bordo da plataforma AQUA. A média e o desvio-padrão de 10 pixels são indicados.

Figure 7-Seasonal variations of (a) NDVI; and (b) EVI obtained from MODIS sensor onboard AQUA platform. Average and standard deviation values of 10 pixels are indicated.

Outros fatores que causam variabilidade nos índices, indicada pelas barras de desvio-padrão nas Figuras 4 e 7 , são as variações do ângulo zenital solar e do ângulo zenital de visada. Do período chuvoso para o seco, o ângulo zenital solar varia cerca de $25^{\circ}$. Ele também varia em menor proporção ao longo de uma cena e entre as plataformas em função dos diferentes horários de passagem dos satélites (10h30 para o TERRA e 13 h30 para o AQUA). Em relação ao ângulo zenital de visada, pixels que foram vistos pelo sensor com visada fora do nadir estão mais sujeitos aos efeitos atmosféricos e direcionais da vegetação (GALVÃO et al., 2004; XAVIER e GALVÃO, 2005). No presente estudo, como exemplo, $10 \%$ dos pixels selecionados para compor o produto MOD13 foram observados com ângulos zenitais de visada superiores a $20^{\circ}$, o que introduz variabilidade na resposta espectral de dada fitofisionomia.

\section{CONCLUSÕES}

(1) Conforme preconizado na literatura, as cinco fitofisionomias estudadas mostraram perfis de NDVI e EVI consistentes com a dinâmica sazonal da vegetação, com maiores valores de índices na estação chuvosa (novembro a abril) e menores valores na estação seca (maio a outubro). Entretanto, fitofisionomias como a Floresta Estacional decídua mostraram forte redução nos valores dos índices da estação chuvosa para a seca, em função da forte perda de folhas, e um ganho acentuado nesses índices devido ao rápido verdejamento da vegetação em resposta à precipitação. Quando comparado com o EVI, o NDVI mostrou maior variabilidade entre as classes de vegetação na estação seca e menor variabilidade na estação chuvosa.

(2) A discriminação entre as fitofisionomias melhorou da estação chuvosa para a seca, período em que se verificou máxima separabilidade espectral. Em termos de separabilidade entre as fitofisionomias, o NDVI apresentou melhor desempenho que o EVI na estação seca, mas o contrário ocorreu na estação chuvosa.

(3) Os índices NDVI e EVI não apresentaram diferenças estatisticamente significativas entre as plataformas TERRA e AQUA na caracterização da dinâmica sazonal da vegetação. As datas em que foram verificadas diferenças estiveram associadas principalmente ao período chuvoso, em que a contaminação por nuvens introduz variabilidade espectral em alguns pixels selecionados para compor as composições de 16 dias.

R. Árvore, Viçosa-MG, v.31, n.2, p.295-305, 2007 
(4) Os resultados indicam potencialidades da utilização dos dados e produtos do MODIS para o monitoramento sazonal contínuo deste bioma com resolução espacial moderada e alta resolução temporal. A alta resolução temporal é necessária para a detecção de mudanças sazonais sutis em fitofisionomias do Cerrado, como o efeito de verdejamento descrito no trabalho, que não é perceptível por sensores como os da série Landsat.

\section{AGRADECIMENTOS}

Ao CNPq e à CAPES, pelo financiamento do trabalho; ao IBAMA, pela autorização dos estudos em campo; à Agência Nacional de Águas (ANA), pela disponiblização dos dados pluviométricos; e à Distributed Active Archive Center (DAAC/NASA), pelo fornecimento dos dados do sensor MODIS. Também ao Dr. Flávio Deppe e aos dois revisores anônimos, pelas sugestões, que permitiram a melhoria do texto.

\section{REFERÊNCIAS}

DESSAY, N. et al. Comparative study of the 19821983 and 1997-1998 El Niño events over different types of vegetation in South America.

International Journal of Remote Sensing, v.25, n.20, p.4063-4077, 2004.

FERREIRA, L.G.; HUETE, A.R. Assessing the seasonal dynamics of the Brazilian Cerrado vegetation through the use of spectral vegetation indices. International Journal of Remote Sensing, v.25, n.10, p.1837-1860, 2004.

FRANÇA, H.; SETZER, A.W. AVHRR temporal analysis of a savanna site in Brazil.

International Journal of Remote Sensing, v.19, n.10, p.3127-3140, 1998.

GALVÃO, L.S. et al. Sun and view angle effects on NDVI determination of land cover types in the Brazilian Amazon region with hyperspectral data. International Journal of Remote Sensing, v.25, n.10, p.1861-1879, 2004.

GURGEL, H.C.; FERREIRA, N.J. Annual and interannual variability of NDVI in Brazil and its connections with climate. International Journal of Remote Sensing, v.24, n.18, p.3595-3609, 2003.

R. Árvore, Viçosa-MG, v.31, n.2, p.295-305, 2007
HANSEN, M.C. et al. Development of a MODIS tree cover validation data set for Western Province, Zambia. Remote Sensing of Environment, v.83, n.1-2, p.320-335, 2002.

HUETE, A.R. et al. A comparison of vegetation indices over a global set of TM images. Remote Sensing of Environment, v.59, n.3, p.440-451, 1997.

HUETE, A.R.; JUSTICE, C.; van LEEUWEN, W. MODIS vegetation Index (MOD13). 1999. 142p. (Algorithm Theoretical Basis Document., v.3; NASA EOS Doc.). Disponível em [http:// modis-land. gsfc.nasa.gov/pdfs/ atbd_mod13.pdf].

HUETE, A.R. et al. Overview of the radiometric and biophysical performance of the MODIS vegetation indices. Remote Sensing of Environment, v.83, v.1-2, p.195-213, 2002.

INSTITUTOBRASILEIRODEGEOGRAFIAE ESTATÍSTICA - IBGE. Manual técnico da vegetação do Brasil. Rio de Janeiro: 1992, 92p.

INSTITUTO BRASILEIRO DE GEOGRAFIA E ESTATÍSTICA - IBGE. Mapa de vegetação do Brasil. Rio de Janeiro: 2004.

JUSTICE, C.O. et al. The Moderate Resolution Spectroradiometer (MODIS): land remote sensing for global research. IEEE Transactions on Geosciences and Remote Sensing, v.36, n.4, p.1228-1249, 1998.

LIESENBERG, V.; GALVÃO, L.S.; PONZONI, F.J. Variations in reflectance with seasonality and viewing geometry: implications for classification of Brazilian savanna physiognomies with MISR/ Terra data. Remote Sensing of

Environment, v.107, n.1-2, p.276-286, 2007.

RATANA, P.; HUETE, A.R.; FERREIRA, L.G. Analysis of Cerrado physiognomies and conversion in the MODIS seasonal-temporal domain. Earth Interactions, v.9, n.3, p.1-22, 2005.

RIBEIRO, J.F.; WALTER, T.M.B. Fitofisionomias do bioma Cerrado. In: SANO, S.M; ALMEIDA, S.P. (Ed.). Cerrado: Ambiente e Flora. Brasília: Embrapa, p.89-152, 1998. 
SANO, E.E.; FERREIRA, L.G.; HUETE, A.R.

Synthetic Aperture Radar (L-band) and optical vegetation indices for discriminating the Brazilian savanna physiognomies: a comparative analysis.

Earth Interactions, v.9, n.15, p.1-15, 2005.
XAVIER, A.S.; GALVÃO, L.S. View angle effects on the discrimination of selected Amazonian land cover types from a principal-component analysis of MISR spectra. International Journal of Remote Sensing, v.26, n.17, p.3797-3811, 2005. 